Article

\title{
Influence of Operating Conditions and Crushing Chamber on Energy Consumption of Cone Crusher
}

\author{
Ruiyue Liu ${ }^{1}$, Boqiang Shi ${ }^{1}{ }^{1 *}$, Guoguang $\mathrm{Li}^{1}$ and Hongjun $\mathrm{Yu}^{2}$ \\ 1 School of Mechanical Engineering, University of Science and Technology Beijing, Beijing 100083, China; \\ b20150253@xs.ustb.edu.cn (R.L.); b20160240@xs.ustb.edu.cn (G.L.) \\ 2 Equipment Manufacturing Branch Company of Anshan Iron and Steel Group Mining Co., Ltd., \\ Anshan 114000, China; yhj1958@163.com \\ * Correspondence: shiboqiang@ustb.edu.cn; Tel.: +86-010-6233-2865
}

Received: 1 February 2018; Accepted: 24 April 2018; Published: 1 May 2018

check for updates

\begin{abstract}
This paper provides an energy consumption model and explains how the operating conditions and structural parameters of a crushing chamber affect energy consumption. Energy consumption is closely related to compressive pressure and displacement. The relationship between pressure, displacement and structural parameters is discussed. The influence of operating parameters on pressure and displacement based on the law of motion of material is examined. Energy consumption can be obtained by the product of pressure and displacement. In consideration of the pressure on the liner surface, which varies according to both height and circumference, an infinitesimal method was used to solve the issue of energy consumption. We validated the predicted energy consumption during breakage with experimental data from a PYGB1821 cone crusher which was consistent with the measured results. Finally, we provide an explanation of the influence of operating parameters and structural parameters on compressive pressure and displacement as well as energy consumption.
\end{abstract}

Keywords: cone crusher; energy consumption; crushing chamber; operating conditions; motion law

\section{Introduction}

Cone crushers are commonly used instruments in the secondary and tertiary crushing of rock material in the minerals industry. With the development of the modern social economy, the amount of material needed to be crushed has gradually increased along with a proportional rise in energy consumption. However, cone crushers typically have very low efficiency, which directly relates to their economic benefit [1,2]. Therefore, further studies on energy consumption related to the crushing process are necessary.

Currently, several models are used to estimate the energy requirement during comminution, such as Bond's model and Rittinger's model [2,3]. Bond's model frequently has been used to calculate the energy consumption in comminution [2-4]. However, Bond's model may be not accurate in terms of different particle size distribution. To address this, Lindqvist [5] modified the energy model to estimate the energy consumption for different size distributions. The influence of particle size distribution on energy consumption was also investigated using fractal theory [6-8]. Apart from particle size distribution, particle size and shape may also affect energy requirements [9]. Fengnian Shi [10] estimated the energy required for a desired size reduction using a Julius Kruttschnitt (JK) size-dependent breakage model. A similar study was conducted by Nadolski [11]. Additionally, the minimum practical energy requirements of particle comminution, or threshold energy, was studied using a JK size-dependent breakage model. Bonfils [12] modified the JK size-dependent breakage model which had previously considered the particle shape. However, the relationship between energy and size reduction was found to be discrete according to the above-mentioned energy models. 
Subsequently, Zhang [13] developed a continuum approach for predicting energy consumption in comminution. Nevertheless, energy absorption during breakage is not only consumed by the rock fragmentation process but also dissipated as a result of friction, wear, and acoustic emission. Mütze [14] found that energy consumption caused by flow losses was less than $0.1 \%$ of the energy requirement, despite the fact that the energy which was consumed by pure elastic deformation was almost $15 \%$ [15].

The relationship between energy requirements and size reduction can be obtained by the energy models described above. However, when a crusher is operated at different conditions, the energy requirement cannot be computed according to existing energy models. Consequently, Numbi [16] developed an energy consumption model with two control variables, the speed and closed side setting of the jaw crusher. Johansson [17] estimated energy consumption according to the forces acting on the static jaw. In addition to mathematical modeling, Discrete Element Modelling (DEM) could also be used to simulate energy consumption. Quist $[18,19]$ predicted energy consumption for different closed side setting cases and speeds with DEM techniques. A similar study was conducted by Cleary [20] who found that energy consumption was sensitive to material strength.

In this paper, a mathematical model is introduced to study the influence of operating conditions and structure of a crushing chamber on energy consumption. Then, the mathematical computation tools, Maple and MATLAB, are employed to solve this model. Finally, the model is calibrated on the basis of an industrial experiment.

\section{Energy Consumption Analysis}

The total energy consumption in a cone crusher can be divided into several parts: no-load mechanical energy of the cone crusher, energy consumption during breakage, energy loss due to the wear of mantle and bowl liner, and energy loss caused by thermoplastic effects and sound wave propagation [14]. This paper considers no load energy consumption $E_{0}$ and energy consumption during comminution $E_{1}$. $E_{1}$ may be obtained by the product of force $F$ and displacement $s$ [17]. Therefore, a characteristic equation of energy consumption model can be expressed as equation (1).

$$
E=E_{0}+E_{1}=E_{0}+\int_{0}^{s_{\mathrm{act}}} F(s) d s,
$$

To estimate the energy requirement in size reduction according to Equation (1), pressure $p$ is needed to calculate the force on the liner. Pressure is related to material properties, operating parameters, and structural parameters of the cone crusher.

\section{Prediction Model of Breakage Energy}

\subsection{Crushing Pressure Model of the Liner}

Pressure on the liner surface is influenced by compression ratio $i$ and feed size distribution $\sigma$ for a given material $[17,21]$. Moreover, the compression ratio varies with the speed of mantle and structure parameters, as does crushing pressure, which can be observed in Figure 1. The maximum pressure is at the closed side setting (CSS), while the minimum pressure is at the open side setting (OSS). The pressure at the OSS is approximately equal to 0 . Pressure on the liner surface can be expressed as Equation (2).

$$
p=f_{1}(i, \sigma),
$$




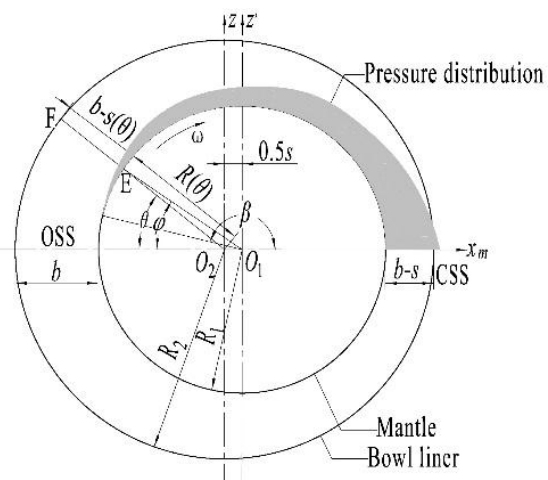

(a)

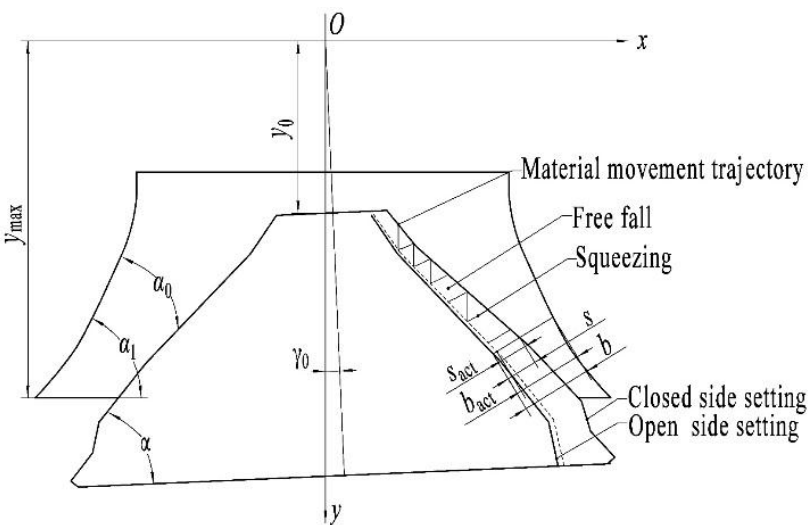

(b)

Figure 1. Cross section of crushing chamber: (a) surface pressure distribution of the mantle; (b) material movement trajectory.

To investigate the pressure on the liner surface, compression ratio should be expressed with the structural parameters of the crushing chamber. Compression ratio, i.e., the ratio of stroke to the height before compression, can be calculated as Equation (3).

$$
i(\theta)=\frac{s(\theta)}{b},
$$

where $b$ represents the height before compression. $s(\theta)$ is the stroke when the mantle rotates angle $\theta$.

The material height before compression is equal to the width of OSS and can be calculated as Equation (4).

$$
b=R_{2}+s / 2-R_{1}
$$

where $R_{2}$ is the radius of bowl liner. $R_{1}$ is the radius of the mantle. Stroke $s$ is a special case of $s(\theta)$.

$s(\theta)$ reflects the compression process, and it is presented in Appendix A.

$$
s(\theta)=R(\theta)+\frac{s}{2}-R_{1}
$$

where

$$
\begin{gathered}
R(\theta)=\sqrt{R_{1}^{2}-\frac{s^{2} \sin ^{2} \theta}{4}}-\frac{s \cos \theta}{2}, \\
s=2 \gamma_{0} \sqrt{R_{1}^{2}+y^{2}},
\end{gathered}
$$

Consequently, we can obtain the variation of $s(\theta)$ according to Equations (5)-(7). s( $\theta)$ increases nonlinearly with rotation angle, as shown in Figure 2. The growth rate of $s(\theta)$ presents an increasing trend from 0 to $\pi / 2$. Nevertheless, it shows the opposite trend between $\pi / 2$ and $\pi$.

Finally, the compression ratio can be obtained by Equations (3)-(7). However, the compression ratio is also influenced by the speed of the mantle. A higher speed is preferred to ensure high productivity of the cone crusher. When the mantle is operated at a higher speed, the actual compression ratio $i_{\text {act }}$ may be less than the nominal compression ratio $i$, and the material will pass through the crushing chamber by free fall and squeezing, as shown in Figure 1b. Clearly, the actual stroke $s_{\text {act }}$ is less than $s$ when the mantle accelerates away rapidly enough. Taking crushing zone $m$ as an example (Figure 3), the material first falls from $A_{2 m}$ to $A_{2 m+1}$. Time of free fall is $t_{m+1}$. Next, it is squeezed from $\mathrm{A}_{2 m+1}$ to $\mathrm{A}_{2 m+2}$. Squeezing time is $t_{m+2}$. The coordinates of $\mathrm{A}_{2 m}, \mathrm{~A}_{2 m+1}$ and $\mathrm{A}_{2 m+2}$ are $\left(x_{2 m}, y_{2 m}\right)$, $\left(x_{2 m+1}, y_{2 m+1}\right)$, and $\left(x_{2 m+2}, y_{2 m+2}\right)$, respectively. $n$ is the mantle speed. $k$ is the actual stroke coefficient. 
When the initial point coordinates are given, the actual stroke and material height (Appendix A) can be calculated according to Figure 4 .

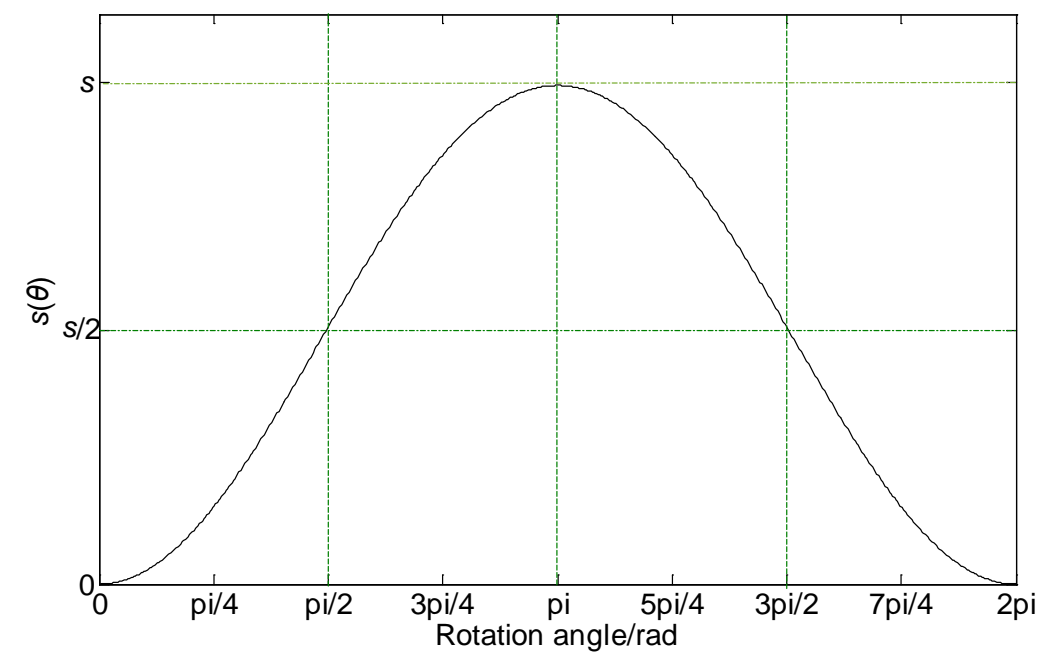

Figure 2. The variation of $s(\theta)$.
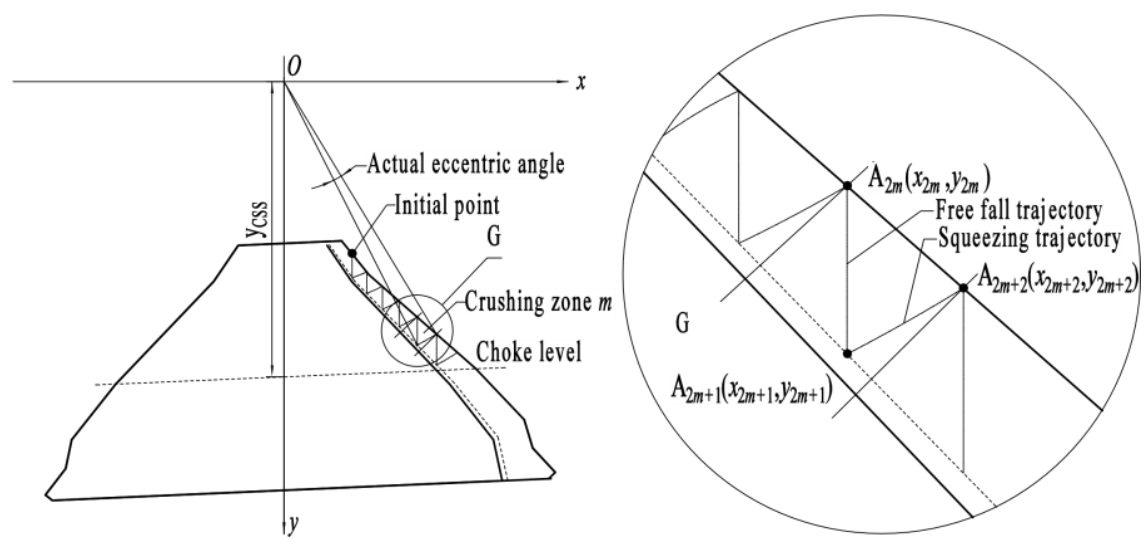

Figure 3. Crushing zone $m$.

Then $i_{\text {act }}$ can be written as Equation (8).

$$
i_{\mathrm{act}}(\theta)=\frac{s_{\mathrm{act}}(\theta)}{b_{\mathrm{act}}}=\frac{s(\theta+\beta-\pi)}{R_{2}+0.5 s_{\mathrm{act}}(\pi)-R_{1}},
$$

The other influence factor of crushing pressure, i.e., size distribution coefficient, represents the dispersion of particle size.

$$
\sigma=\sqrt{\sum_{j=1}^{q} \lambda_{j}\left(\bar{d}_{j}-\bar{d}\right)^{2}} / \bar{d},
$$

where $\lambda_{j}$ is the yield of particle size $j . q$ is the number of particle sizes. $\bar{d}_{j}$ is determined by the mean size of particle $j . \bar{d}$ is the average size of all particles.

Finally, the crushing pressure can be obtained by Equations (2), (8) and (9). 


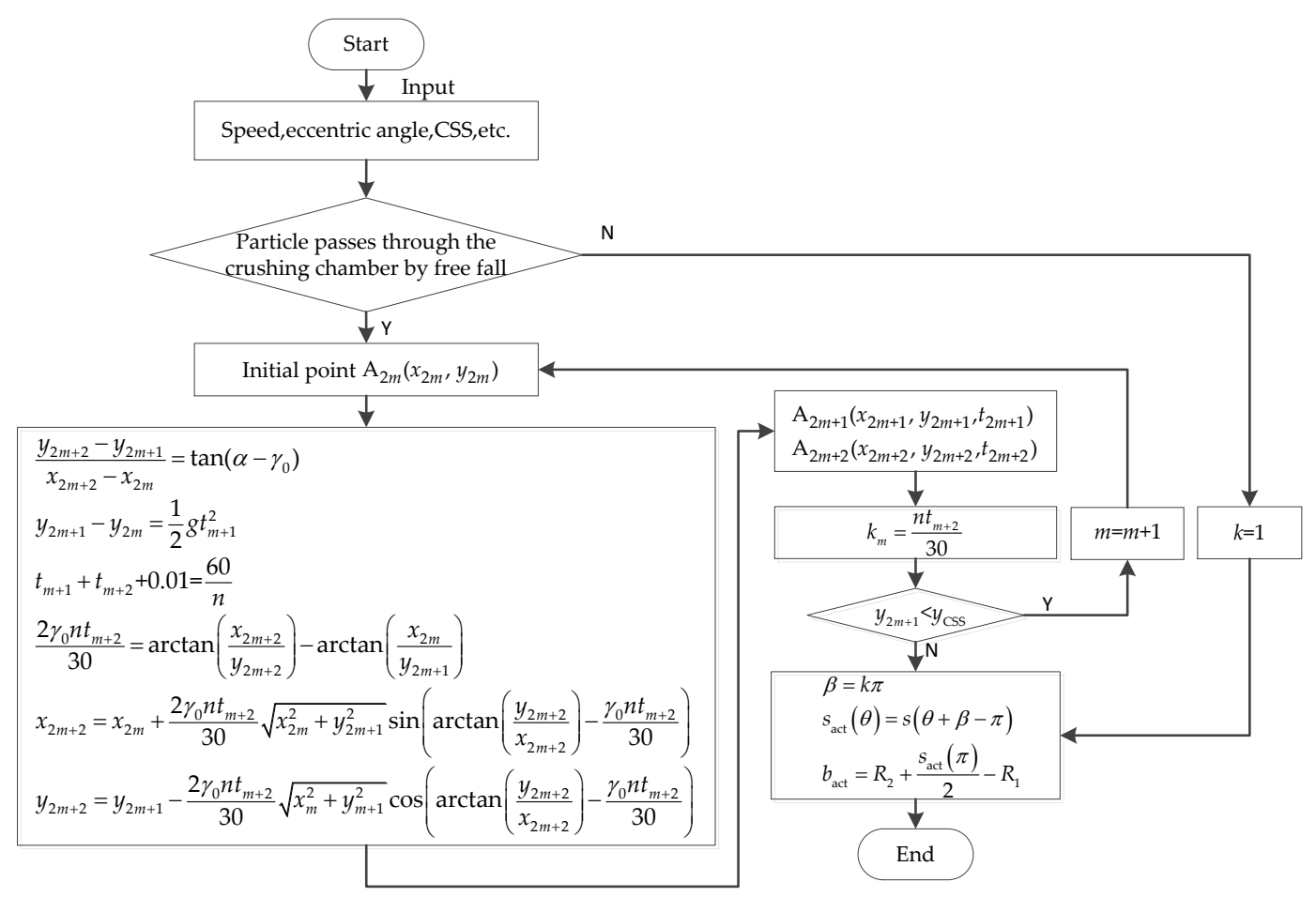

Figure 4. The flow chart of actual stroke coefficient.

\subsection{Modeling of Energy Consumption}

The product of crushing pressure, projected area of the mantle, and the stroke is equal to the work performed by the mantle. The work is then multiplied by the speed of mantle according to Equation (10).The equation corresponds to the energy consumption during rock fragmentation.

$$
\begin{aligned}
E_{1} & =\frac{16.667 n}{\cos \alpha} \int_{0}^{s_{\text {act }}} \int_{0}^{A_{\text {act }}} p\left(i_{\text {act }}, \sigma\right) d A d s \\
& =\frac{16.667 n}{\cos \alpha} \int_{y_{0}}^{y_{\max }} \int_{0}^{s_{\text {act }}} \int_{0}^{l_{\text {act }}} p\left(i_{\text {act }}, \sigma\right) d l d s d y
\end{aligned}
$$

where $A_{\text {act }}$ is the projected area of the mantle and equals the product of arc length $l$ and the height of the mantle. $y_{0}$ is the distance between the suspension point $O$ and the top of the mantle. $y_{\max }$ is the distance between the suspension point and the bottom of the bowl. $l_{\text {act }}$ is the actual arc length of mantle during squeezing.

However, the motion of mantle is not a simple rotation around its axis. It is difficult to perform an integral for Equation (10). Therefore, coordinate transformation was performed to simplify the calculation. The $z$-axis was translated to the position where $x=s / 2$. The rotation angle of mantle changed from $\theta$ to $\phi$ correspondingly, as shown in Figure 1a. Then, the rotation angle $\phi$ could be obtained according to the law of sines.

$$
\varphi=\theta-\arcsin \frac{s \sin \theta}{2 R_{1}},
$$

Thus, energy consumption can be expressed as Equation (12).

$$
E=E_{0}+\frac{16.667 n}{\cos \alpha} \int_{y_{0}}^{y_{\max }} \int_{(1-k) \pi}^{\pi} \int_{0}^{R(\varphi)+s / 2-R_{1}} p\left(i_{\mathrm{act}}, \sigma\right) R_{1} d s(\varphi) d \varphi d y,
$$

Energy consumption per hour could be calculated according to Equation (12). The energy conservation of a crusher is particularly important and attracts considerable attention. However, 
the energy requirement per hour cannot estimate whether the cone crusher is energy-efficient or not. It could be evaluated by the energy consumption per unit production. Therefore, it was necessary to calculate the production of the cone crusher. The production $Q$ equals to the integral of mass-flow field over the choke level of crushing chamber [22].

$$
Q=60 n \rho\left\{\int_{\pi}^{(3-k) \pi} \int_{0}^{\frac{60(\theta-k \pi)}{2 \pi n}} R_{2}\left[R_{2}-R(\theta)\right] v_{\text {down }} d t_{\text {down }} d \theta-\int_{(1-k) \pi}^{\pi} \int_{\frac{60(1-k) \pi}{2 \pi n}}^{\frac{60 \theta}{2 \pi n}} R_{2}\left[R_{2}-R(\theta)\right] v_{\text {up }} d t_{\text {up }} d \theta\right\}
$$

where $\rho$ is the material density. $v_{\text {down }}$ is the free fall velocity of material. $v_{\text {up }}$ is the upward speed of material. $t_{\text {down }}$ is the free fall time. $t_{\mathrm{up}}$ is the squeezing time.

According to Equations (12) and (13), energy consumption per unit production can be presented as Equation (14).

$$
\begin{aligned}
\bar{E} & =\frac{E}{Q} \\
& =\frac{E_{0} \cos \alpha+16.667 n \int_{y_{0}}^{y_{\max }} \int_{\pi-\varphi}^{\pi} \int_{0}^{R(\varphi)+s-R_{1}} p\left(i_{\text {act }}, \sigma\right) R_{1} d s(\varphi) d \varphi d y}{Q \cos \alpha}
\end{aligned}
$$

\section{Example}

\subsection{Experiment}

To verify the model of energy consumption, industrial experiments were conducted on a PYGB1821 cone crusher at Anshan Iron and Steel Group Mining Co., Ltd. (Anshan, China). Energy consumption, feed size distribution, and structural parameters of the crushing chamber were measured. Table 1 shows

\begin{tabular}{|c|c|c|c|c|c|}
\hline $\begin{array}{c}\text { Energy } \\
\text { Consumption } \\
/(\mathbf{k W} \cdot \mathbf{h})\end{array}$ & $\begin{array}{l}\text { Material } \\
\text { Level/\% }\end{array}$ & $\begin{array}{c}\text { Energy } \\
\text { Consumption } \\
/(\mathrm{kW} \cdot \mathrm{h})\end{array}$ & $\begin{array}{l}\text { Material } \\
\text { Level/\% }\end{array}$ & $\begin{array}{c}\text { Energy } \\
\text { Consumption } \\
/(\mathrm{kW} \cdot \mathrm{h})\end{array}$ & $\begin{array}{c}\text { Material } \\
\text { Level/\% }\end{array}$ \\
\hline 235.03 & 0 & 374.28 & 65.51 & 374.03 & 60.45 \\
\hline 235.77 & 0 & 370.20 & 65.80 & 375.03 & 58.33 \\
\hline 235.52 & 0 & 387.50 & 66.98 & 376.69 & 57.64 \\
\hline 235.03 & 0 & 387.33 & 67.82 & 369.04 & 56.60 \\
\hline 239.1 & 0 & 391.90 & 67.45 & 391.15 & 63.14 \\
\hline 245.33 & 0 & 383.42 & 67.68 & 391.15 & 64.06 \\
\hline 245.08 & 0 & 384.67 & 67.77 & 393.82 & 63.40 \\
\hline 244.17 & 0 & 402.71 & 68.50 & 424.33 & 65.36 \\
\hline 245.83 & 0 & 407.03 & 67.13 & 424.33 & 62.85 \\
\hline 242.01 & 0 & 386.58 & 69.21 & 402.71 & 62.38 \\
\hline 244.67 & 0 & 399.30 & 70.23 & 402.71 & 63.72 \\
\hline 241.76 & 0 & 384.67 & 67.13 & 375.03 & 67.25 \\
\hline 244.17 & 0 & 394.48 & 67.91 & 384.67 & 69.36 \\
\hline 242.01 & 0 & 382.51 & 68.00 & 386.58 & 69.21 \\
\hline 376.94 & 70.02 & 396.23 & 68.87 & 375.03 & 67.59 \\
\hline 380.10 & 62.50 & 399.80 & 70.28 & 396.64 & 71.38 \\
\hline 371.45 & 66.29 & 387.08 & 57.06 & 379.85 & 62.64 \\
\hline 370.95 & 66.03 & 372.86 & 53.27 & 373.86 & 61.2 \\
\hline 373.86 & 65.89 & 380.60 & 60.39 & 374.53 & 59.81 \\
\hline 380.35 & 66.72 & 374.53 & 61.89 & 369.29 & 59.03 \\
\hline 383.42 & 67.39 & 379.85 & 62.64 & 387.33 & 67.53 \\
\hline 380.35 & 66.72 & 373.86 & 61.20 & 378.19 & 65.83 \\
\hline
\end{tabular}
the energy consumption of the cone crusher.

Table 1. Energy consumption and material level.

Material density was $2730 \mathrm{~kg} / \mathrm{m}^{3}$. Feed particle size distribution was as shown in Table 2. 
Table 2. Feed particle size distribution.

\begin{tabular}{cccc}
\hline \multirow{2}{*}{ Particle Size/mm } & \multicolumn{3}{c}{ Feed Size Distribution/\% } \\
\cline { 2 - 4 } & \multicolumn{3}{c}{ Test Number } \\
\cline { 2 - 4 } & $\mathbf{1}$ & $\mathbf{2}$ & $\mathbf{3}$ \\
\hline+100 & 2.51 & 4.13 & 1.87 \\
$-100 \sim+66$ & 8.69 & 13.25 & 12.05 \\
$-66 \sim+42$ & 19.42 & 16.73 & 22.03 \\
$-42 \sim+30$ & 19.39 & 18.34 & 17.92 \\
$-30 \sim+24$ & 15.13 & 12.72 & 11.35 \\
$-24 \sim+12$ & 30.31 & 32.17 & 30.77 \\
$-12 \sim+7$ & 3.34 & 1.97 & 3.52 \\
$-7 \sim+5$ & 0.27 & 0.13 & 0.29 \\
$-5 \sim 0$ & 0.94 & 0.56 & 0.20 \\
\hline
\end{tabular}

Table 3 shows the parameters of cone crusher.

Table 3. Structural parameters of crushing chamber and operating parameters.

\begin{tabular}{|c|c|}
\hline Coefficient & Value \\
\hline Maximum radius of the mantle/m & 0.8039 \\
\hline Maximum radius of the bowl liner $/ \mathrm{m}$ & 0.917 \\
\hline Abscissa of initial point $/ \mathrm{m}$ & 0.1878 \\
\hline Ordinate of initial point $/ \mathrm{m}$ & 0.3333 \\
\hline Ordinate of CSS $/ \mathrm{m}$ & 0.727 \\
\hline Height under the suspension point $O / \mathrm{m}$ & 0.3412 \\
\hline Height of bowl liner $/ \mathrm{m}$ & 0.8732 \\
\hline Base angle of mantle ${ }^{\circ}$ & 50.5 \\
\hline Base angle of bowl liner $/^{\circ}$ & 48 \\
\hline Nip angle $/{ }^{\circ}$ & 21 \\
\hline Eccentric angle $/^{\circ}$ & 2.5 \\
\hline Closed set setting $/ \mathrm{mm}$ & 19 \\
\hline Speed/(r/min) & 300 \\
\hline
\end{tabular}

Crushing pressure is necessary to compute the energy consumption and can be obtained by the piston and die test. The pressure required to compress material to a given compression ratio is equal to the pressure response in the piston [9]. Pressures, which were recorded at the piston tests, could be used for the establishment of the pressure model. According to Bengtsson [9], the pressure is influenced by the compression ratio and feed size distribution. Accordingly, the pressure on unit area can be expressed as follow [23].

$$
p=i^{2}\left(-263.01 \sigma^{2}+393.673 \sigma-51.603\right)+i\left(189.563 \sigma^{2}-127.947 \sigma+51.452\right),
$$

\subsection{Results Analysis}

We assumed that the no-load energy consumption was constant at the given speed [16]. According to Table 1, average no-load energy consumption and total energy consumption were $241.11 \mathrm{~kW} \cdot \mathrm{h}$ and $385.10 \mathrm{~kW} \cdot \mathrm{h}$, respectively. The simulated energy consumption could be obtained by Equation (12), and it was $383.52 \mathrm{~kW} \cdot \mathrm{h}$. The simulated value was $1.58 \mathrm{~kW} \cdot \mathrm{h}$ less than the average experimental value. Moreover, the $95 \%$ confidence interval of energy consumption ranged from $381.56 \mathrm{~kW} \cdot \mathrm{h}$ to $388.63 \mathrm{~kW} \cdot \mathrm{h}$. The simulated value was in the $95 \%$ confidence interval. Therefore, the model could be used to predict the energy consumption of the cone crusher. 


\subsection{Influencing Factors of Energy Consumption}

Energy consumption is related to the pressure and displacement in the direction of pressure. For the given rock material, the pressure primarily depends on the compression ratio. Accordingly, the compression ratio and displacement are predominantly influenced by mantle speed and structure parameters of the crushing chamber in the cone crusher. As illustrated in Figure 5a, actual compression ratio presented a downward trend with the increase of speed. Notably, the compression ratio had a positive correlation with the pressure, and the compression ratio and pressure under different speeds shared a similar trend. Figure $5 \mathrm{~b}$ shows the relationship between pressure and actual stroke.

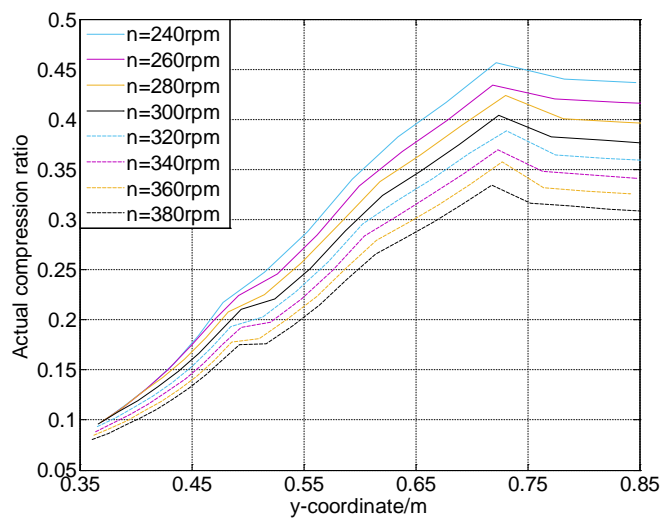

(a)

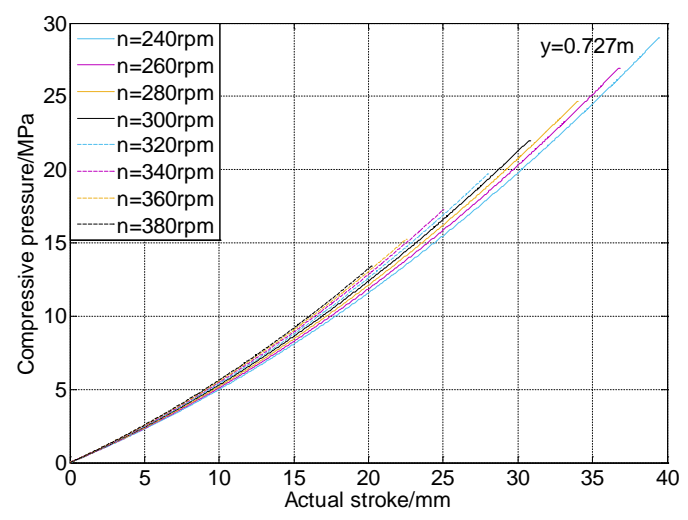

(b)

Figure 5. Compression ratio and pressure for various speeds: (a) relation of compression ratio vs. the height of mantle; (b) relation of compressive pressure vs actual stroke.

Displacement, the other influencing factor of energy consumption with different speeds, depends on the effective squeezing time and squeezing velocity. First, effective squeezing time was calculated based on Figure 4. As shown in Figure 6, the color-filled markers represent actual squeezing time. When the mantle ran at a speed lower than $340 \mathrm{rpm}$, actual squeezing time equaled $30 / n$. While the speed was more than $360 \mathrm{rpm}$, actual squeezing time was less than 30/n. Namely, the higher the speed, the less squeezing time, which indicated lower energy utilization. Moreover, actual squeezing time gradually decreased in proportion to increase in compression number.

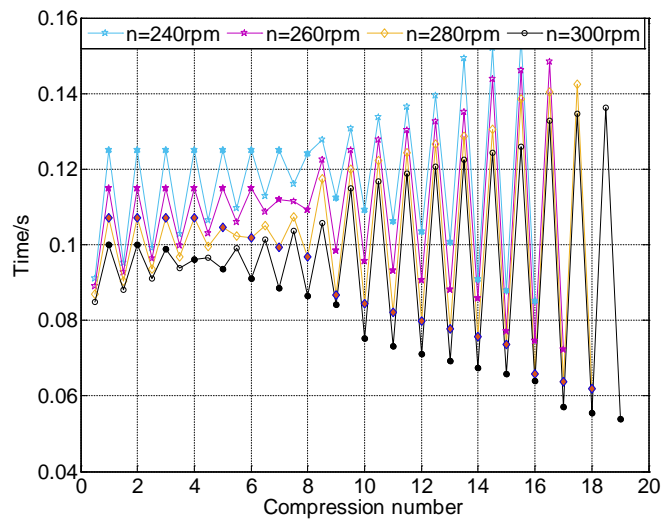

(a)

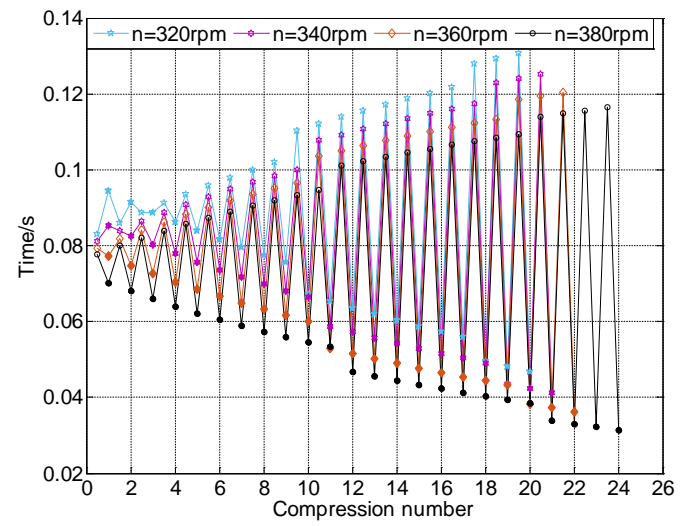

(b)

Figure 6. The influence of speed on squeezing time: (a) relation of compression number vs. squeezing time with speed ranging from $240 \mathrm{rpm}$ to $300 \mathrm{rpm}$; (b) relation of compression number vs. squeezing time with speed ranging from $320 \mathrm{rpm}$ to $380 \mathrm{rpm}$. 
Next, the velocity under different mantle speeds was calculated [22]. Figure 7a illustrates the variation of the velocity particularly within the squeezing process. The maximum squeezing velocity should be at the angle of $\pi / 2$. When the speed was greater than $360 \mathrm{rpm}$, squeezing velocity gradually decreased, which was not beneficial to crushing rock material. Next, displacement is shown in Figure $7 \mathrm{~b}$. It was observed that the actual stroke increased in relationship to a decrease of speed. That is to say, the stroke had a negative correlation with speed.

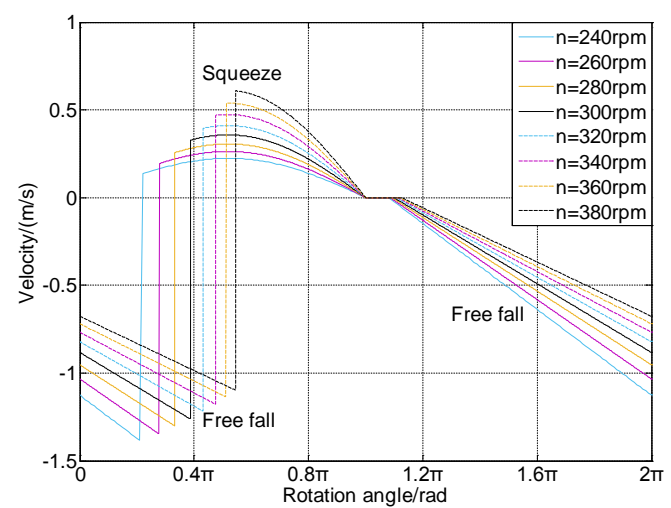

(a)

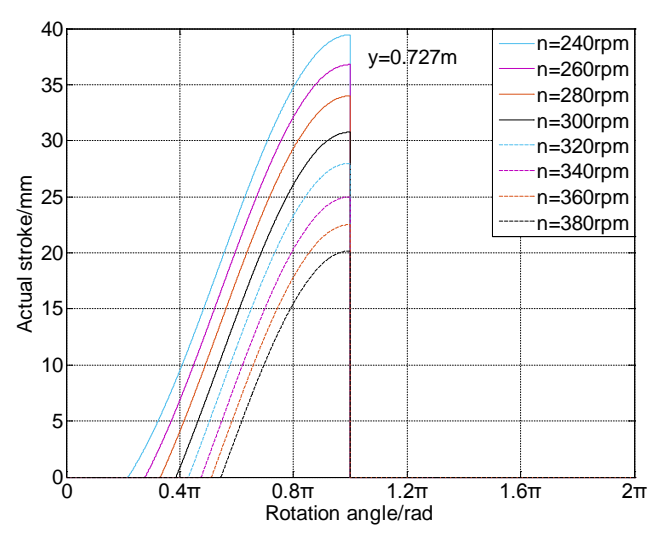

(b)

Figure 7. Squeezing velocity and actual stroke for various speed: (a) relation of speed vs. squeezing velocity; (b) relation of speed and actual stroke.

Finally, energy consumption under different speeds was computed based on Equation (10). It can be seen from Figure 8 that speed had significant effects on energy consumption. Energy consumption during breakage at $280 \mathrm{rpm}$ was about $73.96 \%$ as much as that at $240 \mathrm{rpm}$. Moreover, breakage energy had a positive correlation with speed. However, this did not indicate energy consumption presented an upward tendency with the increase of speed, as illustrated in Figure 8b. The energy consumption was also influenced by the no-load mechanical energy of the cone crusher: the higher the speed, the more no-load energy consumption, and the less energy consumption during breakage. Therefore, energy consumption could fluctuate with the increase of speed.

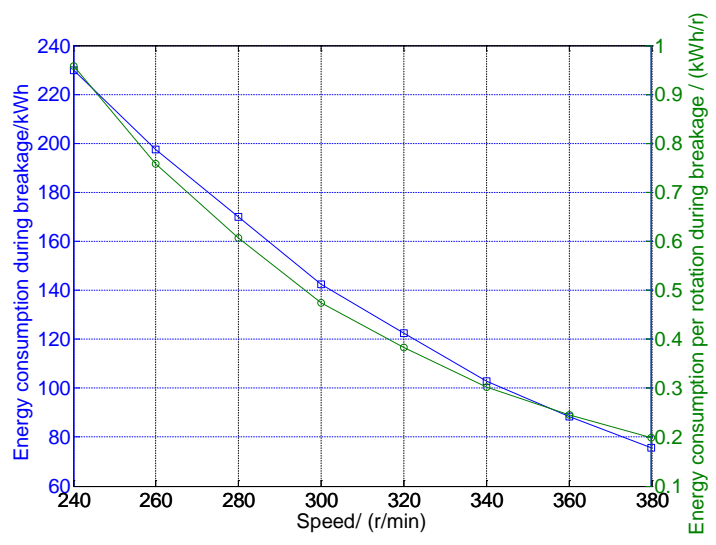

(a)

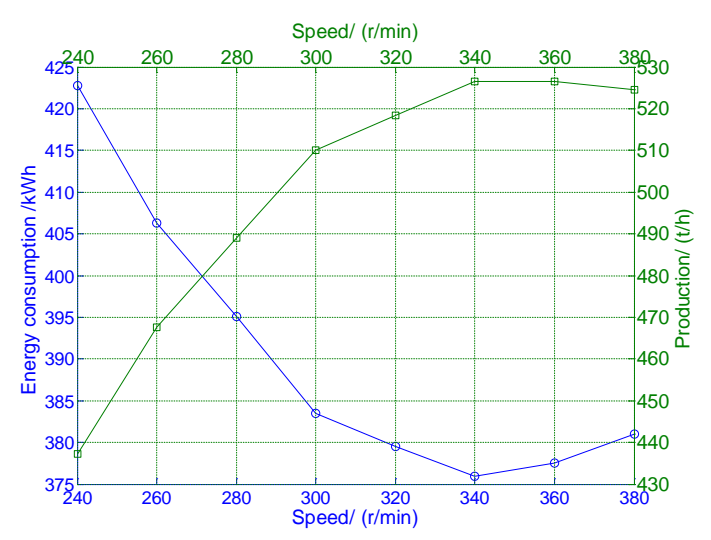

(b)

Figure 8. Energy consumption and production when varying speed: (a) relation of speed vs. energy consumption during breakage; (b) relation of speed, production and energy consumption.

The structural parameters of a crushing chamber predominantly include the eccentric angle, nip angle, CSS, etc. The influence of eccentric angle and nip angle on compressive pressure is presented 
in Figure 9. The increase of eccentric angle leads to an increase of pressure. As eccentric angle is directly proportional to the stroke $s$, and $b$ is almost invariant. Accordingly, it can be concluded that compression ratio presents a positive correlation with eccentric angle according to Equation (3), as does the pressure. Therefore, breakage energy increased with eccentric angle and speed, as shown in Figure 10a. Energy consumption of a cone crusher may have fluctuated with the increase of speed when the eccentric angle was more than $1.8^{\circ}$, as can be seen in Figure 10b. As such, the proportion of no-load energy consumption in total energy consumption may have changed with the eccentric angle.

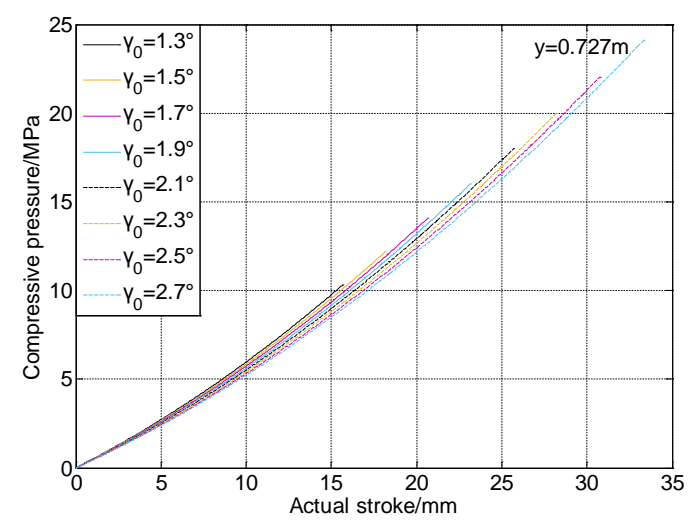

(a)

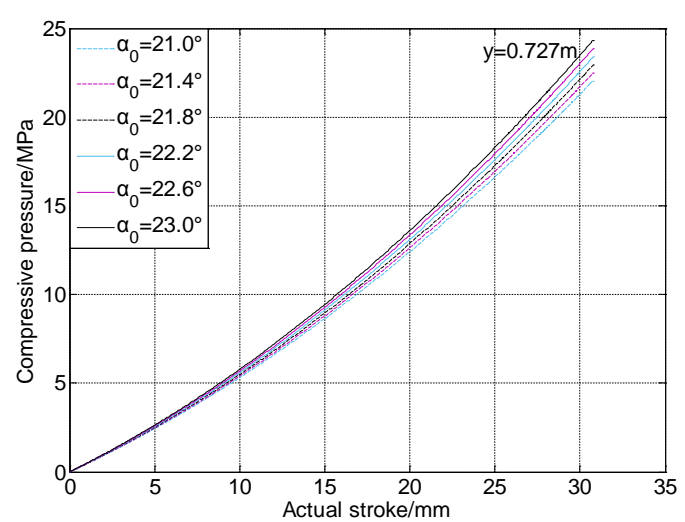

(b)

Figure 9. The influence of eccentric angle and nip angle on pressure: (a) relation of eccentric angle vs. pressure; (b) relation of nip angle and pressure.

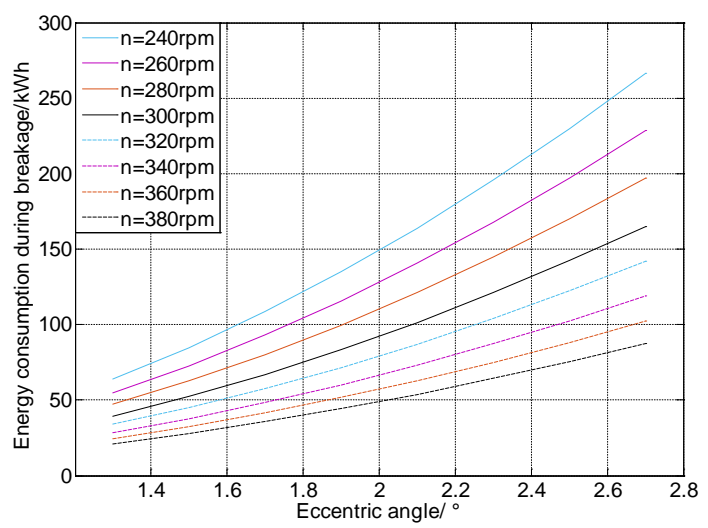

(a)

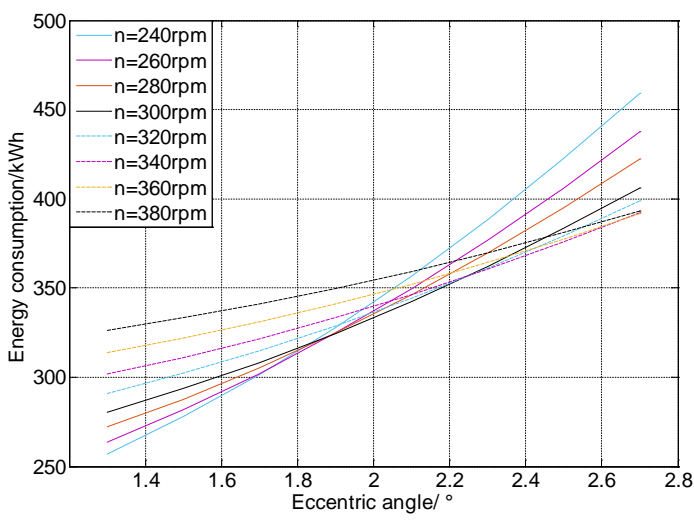

(b)

Figure 10. Energy consumption for various eccentric angle and speed: (a) relation of eccentric angle vs. breakage energy consumption; (b) relation of eccentric angle vs. energy consumption of cone crusher.

The other structural parameter, nip angle, can be expressed as Equation (16).

$$
\alpha_{0}=\alpha_{1}-\left(\alpha \pm \gamma_{0}\right)
$$

where $\alpha_{1}$ is the base angle of bowl liner. Usually, value range of nip angle is $21^{\circ} \sim 23^{\circ}$.

An increase in the nip angle led to a small increase in the energy consumption, as illustrated in Figure 11. The action of nip angle ensured that the rock particle did not slide upwards. The adjustment range of the nip angle was narrow. Additionally, the change of the nip angle was significantly less than the base angle. Therefore, energy consumption was not subjected to the nip angle, according to Equation (10). 


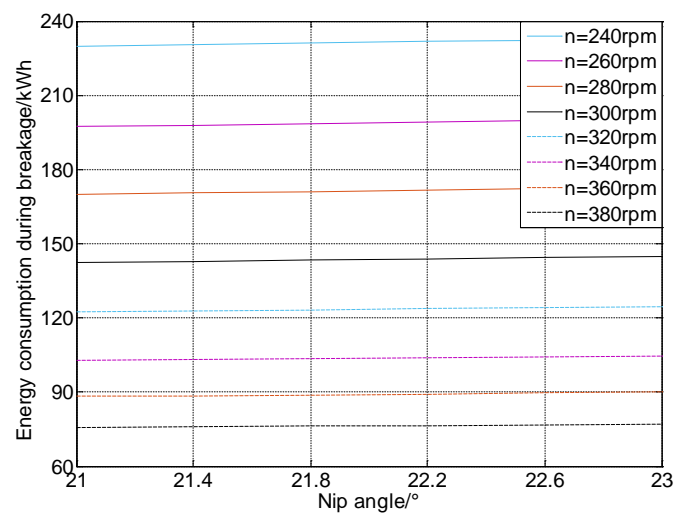

(a)

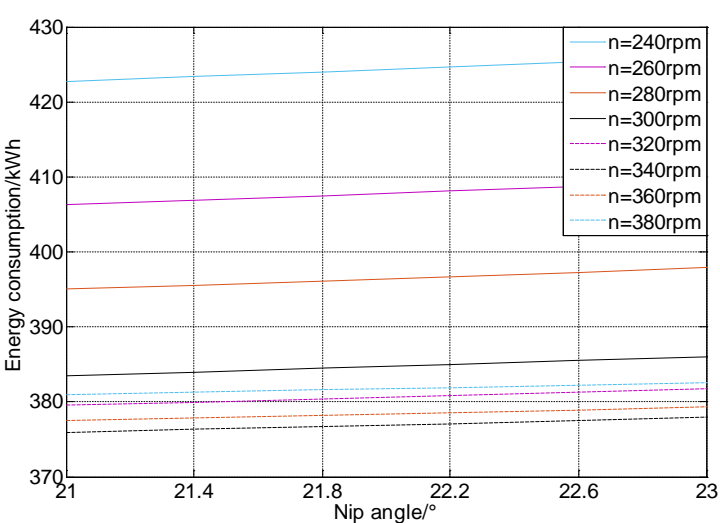

(b)

Figure 11. Energy consumption when varying the nip angle and speed: (a) relation of nip angle vs. breakage energy consumption; (b) relationship of nip angle vs. energy consumption of cone crusher.

Finally, CSS also strongly influenced energy consumption and could be regulated by adjusting the height of the bowl. CSS can be presented as:

$$
\mathrm{CSS}=R_{2}-R_{1}-\frac{S}{2}
$$

Compressive pressure for various CSS can be calculated by Equations (15) and (17). It is clear from Figure 12a that the pressure decreased with an increase of CSS, while the actual stroke remained unchanged. Therefore, the breakage energy consumption showed the same trend with pressure, as shown in Figure 12b. Accordingly, energy consumption can be calculated according to Equation (12). The energy consumption showed a downward trend with an increase of CSS and also in a nonlinear way, as illustrated in Figure 13a CSS is one of the most important factors in determining the product size: the bigger the CSS, the bigger the product size. Thus, the energy requirement in size reduction will decrease. Finally, the relationship among the production, CSS, and energy consumption is as shown in Figure 13b. Energy consumption decreased with an increase of CSS; however, production showed the opposite trend.

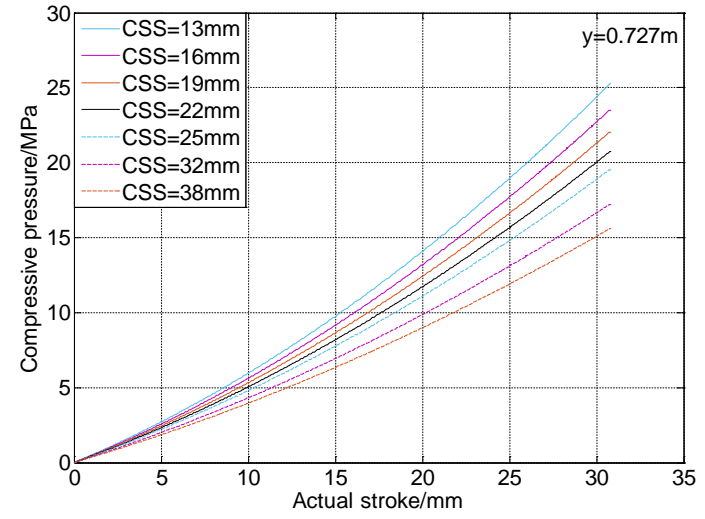

(a)

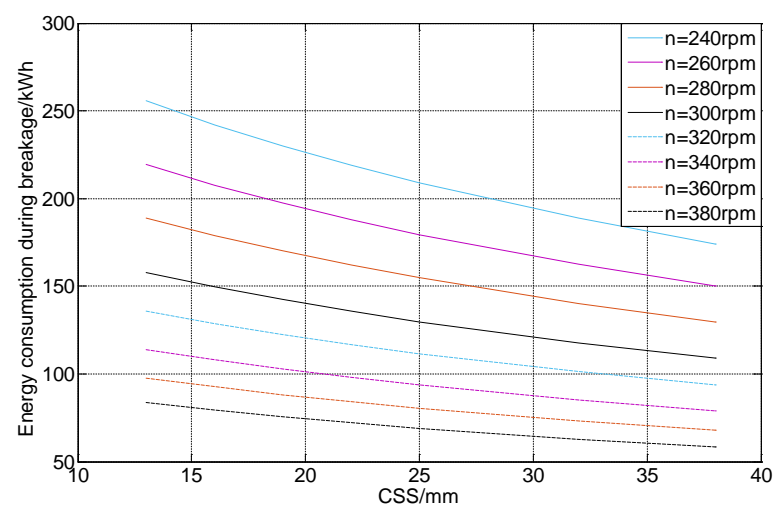

(b)

Figure 12. The influence of CSS on pressure and breakage energy: (a) relation of CSS vs. pressure; (b) relation of CSS vs. breakage energy consumption. 


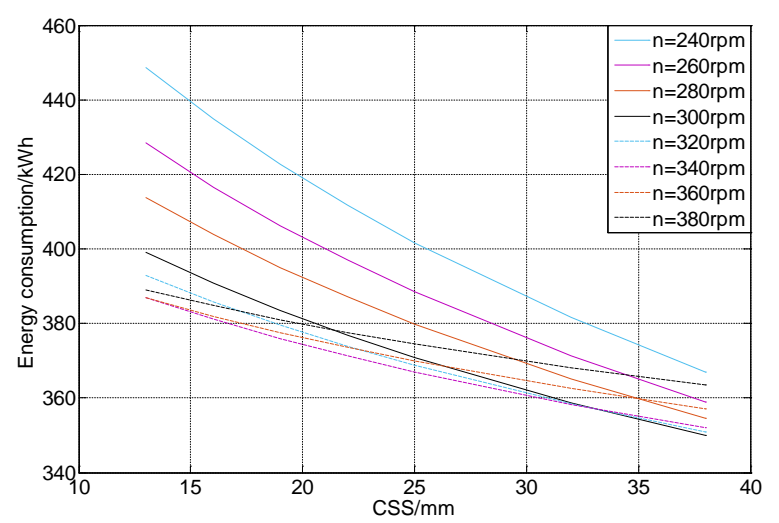

(a)

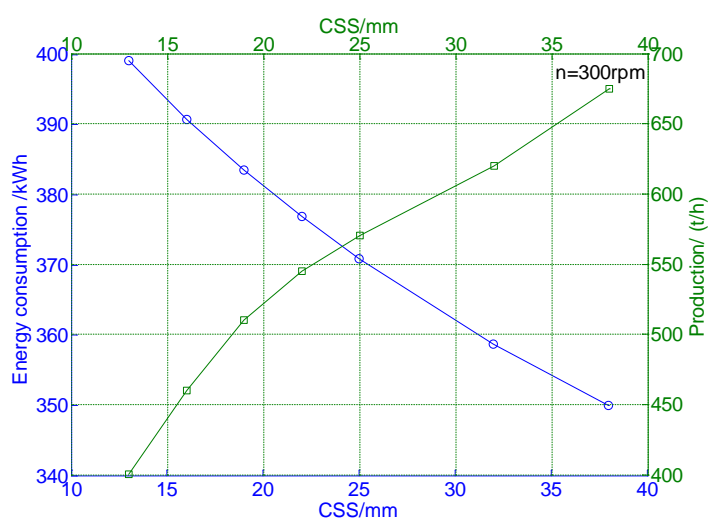

(b)

Figure 13. Relation of CSS and energy consumption: (a) CSS vs. energy consumption; (b) CSS, production and energy consumption.

\section{Discussion}

In the present study, we developed an energy consumption model of a cone crusher and investigated the influence of operating conditions and structure parameters on energy consumption. Our results demonstrated that energy consumption was sensitive to speed, eccentric angle, and CSS. This is notable because it provides guidance for chamber design and energy optimization.

Energy consumption depended on both pressure and displacement. Both the pressure and displacement decreased with an increase in speed. Consequently, breakage energy consumption showed a downward trend with speed, as illustrated in Figures $5 \mathrm{~b}$ and $8 \mathrm{a}$. The result is similar to the findings of Johansson and Cleary $[19,20]$. However, the energy consumption of cone crusher may show different trends with breakage energy consumption because the energy consumption was also influenced by no-load mechanical energy. Therefore, the relationship between energy consumption and speed, either positive or negative correlation, depends on the proportion of breakage energy consumption in total energy consumption. As can be seen from Figure $8 \mathrm{~b}$, energy consumption gradually decreased with an increase in speed. The production increased firstly with speed and then decreased. Moreover, the maximum squeezing velocity was at the angle of $\pi / 2$, as shown in Figure 7a.The design speed should ensure that the initial squeezing velocity of material is less than the maximum squeezing velocity. As a result, speed and production both need to be considered to optimize the energy consumption of the cone crusher.

Structural parameters, eccentric angle, and CSS had a significant influence on the breakage energy consumption. However, this was not the case for the nip angle. Since the eccentric angle was an important factor for the displacement, the greater the displacement, the more pressure was exerted. Accordingly, the breakage energy consumption was correspondingly higher. When the eccentric angle was more than $1.8^{\circ}$, the energy consumption of cone crusher also fluctuated with the increase of speed. Clearly, the eccentric angle affected the speed of minimum energy consumption. CSS is a particle size controller parameter. Both breakage energy consumption and energy consumption of a cone crusher showed a downward trend with an increase of CSS; the size of crushed material increased with CSS. Therefore, the energy which was used to crush the material decreased. This result was in agreement with the findings of Cleary [20]. Surprisingly, the nip angle, which usually ranges from $21^{\circ}$ to $23^{\circ}$, had nearly no influence on energy consumption. The influence of nip angle on pressure and displacement was not obvious. The action of the nip angle is to guarantee that the material does not slide upwards. That is to say, the influence of nip angle on energy consumption could be ignored when we optimized the energy consumption.

The model could be used to show the influence of some parameters on energy consumption, although it exhibited several defects which made the predicted value less than the average experimental 
value. Energy consumption caused by flow losses, thermoplastic effects, and sound wave propagation are ignored. Another explanation for the discrepancy is material heterogeneity. Both the particle size and particle shape may have influence the pressure and energy consumption. These issues could be explored to improve prediction accuracy in a further study.

\section{Conclusions}

A mathematical model was developed to study the influence of speed, eccentric angle, nip angle, and CSS on the energy consumption of a cone crusher. This model was calibrated and validated based on a PYGB1821 crusher at Anshan Iron and Steel Group Mining Co. Ltd.

In general, speed, eccentric angle, and CSS had a significant influence on energy consumption. However, nip angle was found to have negligible influence. The predicted energy consumption at the speed of $240 \mathrm{rpm}$ was $39.25 \mathrm{~kW} \cdot \mathrm{h}$ higher than that at $300 \mathrm{rpm}$. When the speed was $380 \mathrm{rpm}$, the energy consumption was only $90.13 \%$ of that at $240 \mathrm{rpm}$. Moreover, the relationship between energy consumption and speed, either in terms of a positive or negative correlation, was also influenced by eccentric angle. The eccentric angle presented a positive correlation with energy consumption. An increase in eccentric angle from $1.3^{\circ}$ to $2^{\circ}$ (a $53.84 \%$ increase) led to an $18.68 \%$ increment, while the next $53.84 \%$ increase led to a further $27.87 \%$ increment. In addition, when the CSS was $38 \mathrm{~mm}$, the energy consumption was only about $87.68 \%$ as much as that at $13 \mathrm{~mm}$.

The model provides an effective means for quantifying the influence of operating parameters and structural parameters on energy consumption. Furthermore, the model also explains how the operating parameters and structural parameters affect energy consumption. Therefore, the model could be used to provide a reference for further study on how to match and optimize operating parameters and structural parameters.

Author Contributions: Ruiyue Liu and Boqiang Shi conceived and designed the calculations and experiments; Guoguang $\mathrm{Li}$ and Hongjun Yu had contributed to perform the experiments. Ruiyue Liu wrote the paper.

Acknowledgments: The industrial experiments were carried out at Anshan Iron and Steel Group Mining Co., Ltd. Yaoming Su and the others staffs are gratefully acknowledged for providing information and support.

Conflicts of Interest: The authors declare no conflict of interest.

\section{Nomenclature}

A surface area of liner, $\mathrm{m}^{2}$

$b \quad$ material height before compression, $\mathrm{m}$

$b_{\text {act }}$ actual material height before compression, $\mathrm{m}$

CSS closed side setting

$\bar{d} \quad$ the average size of all particles, $\mathrm{mm}$

$\bar{d}_{j} \quad$ the mean size of particle $j, \mathrm{~mm}$

$E \quad$ energy consumption of cone crusher, $\mathrm{kW} \cdot \mathrm{h}$

$E_{0} \quad$ no-load mechanical energy, $\mathrm{kW} \cdot \mathrm{h}$

$E_{1} \quad$ energy consumption during breakage, $\mathrm{kW} \cdot \mathrm{h}$

$F_{\text {stress }}$ stress on the liner, $\mathrm{N}$

i compression ratio

$i_{\text {act }}$ actual compression ratio

$k \quad$ actual stroke coefficient

$l_{\text {act }}$ the actual arc length of mantle during squeezing, $m$

$l$ arc length, $\mathrm{m}$

$m$ crushing zone

$n \quad$ mantle speed, $\mathrm{r} / \mathrm{min}$

O suspension point

OSS open side setting

$\mathrm{O}_{1} \quad$ the center of the mantle 
$\mathrm{O}_{2}$ the center of the bowl liner

$p \quad$ pressure on the mantle, $\mathrm{MPa}$

$q \quad$ the number of particle sizes

$Q \quad$ production, $\mathrm{t} / \mathrm{h}$

$R_{1} \quad$ radius of the mantle, $\mathrm{m}$

$R_{2} \quad$ radius of bowl liner, $m$

$R(\theta) \quad$ distance between the center $\mathrm{O}_{2}$ of the bowl liner and the surface of the mantle, $\mathrm{m}$

$s \quad$ stroke, $\mathrm{m}$

$s_{\text {act }}$ actual stroke, $\mathrm{m}$

$s(\theta) \quad$ the stroke when the mantle rotates angle $\theta, \mathrm{m}$

$t_{\text {down }}$ free fall time of choke level, $\mathrm{s}$

$t_{\text {up }}$ squeezing time of choke level, $\mathrm{s}$

$t_{m+1}$ free fall time of crushing zone $m, \mathrm{~s}$

$t_{m+2}$ squeezing time of crushing zone $m, \mathrm{~s}$

$v_{\text {down }}$ the free fall velocity of material, $\mathrm{m} / \mathrm{s}$

$v_{\text {up }} \quad$ the upward speed of material, $\mathrm{m} / \mathrm{s}$

$y_{\text {css }} \quad$ ordinate of closed side setting, $m$

$y_{\max }$ the distance between the suspension point $O$ and the bottom of the bowl, $\mathrm{m}$

$y_{0}$ the height under the suspension point $O, \mathrm{~m}$

$x_{2 m}$ abscissa of $\mathrm{A}_{2 m}, \mathrm{~m}$

$y_{2 m}$ ordinate of $A_{2 m}, m$

$x_{2 m+1}$ abscissa of $\mathrm{A}_{2 m+1}, \mathrm{~m}$

$y_{2 m+1}$ ordinate of $\mathrm{A}_{2 m+1}, \mathrm{~m}$

$x_{2 m+2}$ abscissa of $\mathrm{A}_{2 m+2}, \mathrm{~m}$

$y_{2 m+2}$ ordinate of $\mathrm{A}_{2 m+2}, \mathrm{~m}$

$\alpha \quad$ base angle of the mantle, ${ }^{\circ}$

$\alpha_{0} \quad$ nip angle, ${ }^{\circ}$

$\alpha_{1} \quad$ base angle of the bowl liner, ${ }^{\circ}$

$\beta \quad$ actual squeezing angle, ${ }^{\circ}$

$\gamma_{0}$ eccentric angle, ${ }^{\circ}$

$\theta \quad$ rotation angle of mantle around the center of bowl liner, ${ }^{\circ}$

$\lambda_{j} \quad$ the yield of particle size $j$

$\rho \quad$ material density, $\mathrm{kg} / \mathrm{m}^{3}$

$\sigma \quad$ feed size distribution

$\varphi \quad$ rotation angle of mantle around its center, ${ }^{\circ}$

\section{Appendix}

(1) Stroke

$s(\theta)$ can be presented as Equation (A1).

$$
s(\theta)=b+R(\theta)-R_{2}
$$

$R(\theta)$ can be calculated according to the law of cosines.

$$
R(\theta)=\sqrt{R_{1}{ }^{2}-\frac{s^{2} \sin ^{2} \theta}{4}}-\frac{s \cos \theta}{2}
$$

The stroke $s$ is expressed as:

$$
s=2 \gamma_{0} \sqrt{R_{1}^{2}+y^{2}}
$$

The material height before compression can be calculated as Equation (A4).

$$
b=R_{2}+s / 2-R_{1}
$$


Substituting Equation (A4) into Equation (A1) gives:

$$
s(\theta)=R(\theta)+\frac{s}{2}-R_{1}
$$

(2) Actual material height and actual stroke

Actual material height is expressed as:

$$
b_{\mathrm{act}}=R_{2}+\frac{s_{\mathrm{act}}(\pi)}{2}-R_{1}
$$

Actual stroke can be presented as:

$$
s_{\text {act }}(\theta)=s(\theta+\beta-\pi)
$$

where

$$
\beta=k \pi
$$

Actual stroke coefficient is expressed as:

$$
k=\frac{n t_{m+2}}{30}
$$

To obtain the actual material height and stroke, it is essential to establish the relation between coordinates and time. The slope of $\mathrm{A}_{2 m+1} \mathrm{~A}_{2 m+2}$ is formulated as:

$$
\frac{y_{2 m+2}-y_{2 m+1}}{x_{2 m+2}-x_{2 m}}=\tan \left(\alpha-\gamma_{0}\right)
$$

The free fall distance of material can be expressed as:

$$
y_{2 m+1}-y_{2 m}=\frac{1}{2} g t_{m+1}^{2}
$$

The motion cycle of mantle is expressed as:

$$
t_{m+1}+t_{m+2}+0.01=\frac{60}{n}
$$

The actual eccentric angle can be formulated as:

$$
\frac{2 \gamma_{0} n t_{m+2}}{30}=\arctan \left(\frac{x_{2 m+2}}{y_{2 m+2}}\right)-\arctan \left(\frac{x_{2 m}}{y_{2 m+1}}\right)
$$

The abscissa of $\mathrm{A}_{2 m+2}$ can be expressed as:

$$
x_{2 m+2}=x_{2 m}+\frac{2 \gamma_{0} n t_{m+2}}{30} \sqrt{x_{2 m}^{2}+y_{2 m+1}^{2}} \sin \left(\arctan \left(\frac{y_{2 m+2}}{x_{2 m+2}}\right)-\frac{\gamma_{0} n t_{m+2}}{30}\right)
$$

The ordinate of $\mathrm{A}_{2 m+2}$ is formulated as:

$$
y_{2 m+2}=y_{2 m+1}-\frac{2 \gamma_{0} n t_{m+2}}{30} \sqrt{x_{m}^{2}+y_{m+1}^{2}} \cos \left(\arctan \left(\frac{y_{2 m+2}}{x_{2 m+2}}\right)-\frac{\gamma_{0} n t_{m+2}}{30}\right)
$$

The coordinates and time can be obtained by solving Equations (A10)-(A15). Finally, calculation results can be used to compute the actual material height and actual stroke.

\section{References}

1. Holmberg, K.; Kivikytö-Reponen, P.; Härkisaari, P.; Valtonen, K.; Erdemir, A. Global energy consumption due to friction and wear in the mining industry. Tribol. Int. 2017, 115, 116-139. [CrossRef]

2. Legendre, D.; Zevenhoven, R. Assessing the energy efficiency of a jaw crusher. Energy 2014, 74, 119-130. [CrossRef] 
3. Petrakis, E.; Stamboliadis, E.; Komnitsas, K. Evaluation of the relationship between energy input and particle size distribution in comminution with the use of piecewise regression analysis. Part. Sci. Technol. 2016, 35, 479-489. [CrossRef]

4. Terva, J.; Kuokkala, V.T.; Valtonen, K.; Siitonen, P. Effects of compression and sliding on the wear and energy consumption in mineral crushing. Wear 2018, 398-399, 116-126. [CrossRef]

5. Lindqvist, M. Energy considerations in compressive and impact crushing of rock. Miner. Eng. 2008, 21, 631-641. [CrossRef]

6. Deng, Y.; Chen, M.; Jin, Y.; Zou, D. Theoretical analysis and experimental research on the energy dissipation of rock crushing based on fractal theory. J. Nat. Gas Sci. Eng. 2016, 33, 231-239. [CrossRef]

7. Martins, S. Size-energy relationship in comminution, incorporating scaling laws and heat. Int. J. Miner. Process. 2016, 153, 29-43. [CrossRef]

8. $\mathrm{Xu}, \mathrm{Y}$; W Wang, Y. Size effect on specific energy distribution in particle comminution. Fractals 2017, $25,1750016$. [CrossRef]

9. Bengtsson, M.; Svedensten, P.; Evertsson, C.M. Characterization of Compressive Breakage Behavior. In Proceedings of the XXIII International Mineral Processing Congress, Istanbul, Turkey, 3-8 September 2006.

10. Shi, F. A review of the applications of the JK size-dependent breakage model part 2: Assessment of material strength and energy requirement in size reduction. Int. J. Miner. Process. 2016, 157, 36-45. [CrossRef]

11. Nadolski, S.; Klein, B.; Kumar, A.; Davaanyam, Z. An energy benchmarking model for mineral comminution. Miner. Eng. 2014, 65, 178-186. [CrossRef]

12. Bonfils, B.; Ballantyne, G.R.; Powell, M.S. Developments in incremental rock breakage testing methodologies and modelling. Int. J. Miner. Process. 2016, 152, 16-25. [CrossRef]

13. Zhang, C.; Nguyen, G.D.; Kodikara, J. An application of breakage mechanics for predicting energy-size reduction relationships in comminution. Powder Technol. 2016, 287, 121-130. [CrossRef]

14. Mütze, T. Energy dissipation in particle bed comminution. Int. J. Miner. Process. 2015, 136, 15-19. [CrossRef]

15. Mütze, T. Modelling the stress behaviour in particle bed comminution. Int. J. Miner. Process. 2016, 156, 14-23. [CrossRef]

16. Numbi, B.P.; Zhang, J.; Xia, X. Optimal energy management for a jaw crushing process in deep mines. Energy 2014, 68, 337-348. [CrossRef]

17. Johansson, M.; Bengtsson, M.; Evertsson, C.M.; Hulthén, E. A fundamental model of an industrial-scale jaw crusher. Miner. Eng. 2017, 105, 69-78. [CrossRef]

18. Quist, J.; Evertsson, C.M. Cone crusher modelling and simulation using DEM. Miner. Eng. 2016, 85, 92-105. [CrossRef]

19. Johansson, M.; Quist, J.; Evertsson, C.M.; Hulthén, E. Cone crusher performance evaluation using DEM simulations and laboratory experiments for model validation. Miner. Eng. 2017, 103-104, 93-101. [CrossRef]

20. Cleary, P.W.; Sinnott, M.D.; Morrison, R.D.; Cummins, S.; Delaney, G.W. Analysis of cone crusher performance with changes in material properties and operating conditions using DEM. Miner. Eng. 2017, 100, 49-70. [CrossRef]

21. Wu, J.; Bai, H.; Li, Q.; Ma, D. Grain size distribution effect on the hydraulic properties of disintegrated coal mixtures. Energies 2017, 10, 612. [CrossRef]

22. Evertsson, C.M. Cone Crusher Performance. Ph.D. Thesis, Chalmers University of Technology, Gothenburg, Sweden, July 2000.

23. Ma, Y.; Fan, X.; He, Q. Prediction of cone crusher performance considering liner wear. Appl. Sci. 2016, 6, 404. [CrossRef]

(C) 2018 by the authors. Licensee MDPI, Basel, Switzerland. This article is an open access article distributed under the terms and conditions of the Creative Commons Attribution (CC BY) license (http://creativecommons.org/licenses/by/4.0/). 